\title{
Applications of X-Ray Computed Tomography in Food Processing
}

Vidhya $\mathbf{M}^{*}$, Varadharaju N, John Kennedy Z, Amirtham D and Manohar Jesudas D

Department of Food and Agricultural Process Engineering, Post-Harvest Technology Centre, Tamil Nadu Agricultural University, Coimbatore, India

\begin{abstract}
X-ray computed tomography $(\mathrm{CT})$ is a technique primarily used in medical applications that uses $\mathrm{X}$-ray images to reconstruct the internal microstructure of objects. This is considered to be a non-destructive and non-invasive technique for 3D imaging of any materials. Using X-rays, a series of radiographs of a sample are recorded from various angles, and then used to reconstruct the internal 3D microstructure by means of a suitable reconstruction algorithm. The method has a high penetrating power and probing efficiency, and is unlimited by morphological complexity. This article summarizes the concept and applications of X-ray computed tomography in various fields of food processing.
\end{abstract}

Keywords: Non-destructive; X-rays; Computed tomography; Internal microstructure; Defects and applications

\section{Introduction}

Quality of any agricultural produce is always of prime concern for success in market. In agricultural industry, the quality evaluation still heavily depends on manual inspection, which is time consuming, laborious and costly. Manual inspection may easily be influenced by physiological factors including subjective and inconsistent evaluation results. Focusing on necessity to improve quality evaluation of food products satisfies greater expectation of consumers, increased awareness and sophistication [1-3]. Non-destructive quality evaluation of agricultural products has become a major area of interest for the agricultural processing industry. A number of non-destructive methods for internal quality evaluation have been studied by different researchers over the past eight decades [4,5]. X-ray and computed tomography imaging techniques are few of them which are gaining popularity now days in various fields of agriculture and food quality evaluation. These techniques, so far predominantly used in medical applications, have also been explored for internal quality inspection of various agricultural products non-destructively, when quality features are not visible on the surface of the products [6]. Though, safety of operators and time required for tests are of concern, the non-destructive nature of these techniques has great potential for wide applications on agricultural produce.

\section{Principle}

The term 'tomography' originates from the Greek words tomos'slices', and graphos-'imaging. X-ray tomographic imaging was introduced in the early 1970s, with its theory being first applied for clinical purposes by Godfrey Hounsfield and Allan Cormack, for which they shared a Nobel Prize. X-ray tomography is a non-invasive technique that allows the visualization of the interior of a specimen via the generation of cross-sectional data [7-12]. An X-ray beam is focused on the studied sample and a shadow image reflecting X-ray attenuation along the beam path is recorded (Figures land 2). The rotation of the sample generates successive images that are stored and subsequently analyzed by computer assisted tomography or CAT scanning.

\section{Applications of $\mathrm{X}$-ray $\mathrm{CT}$ in various fields of food processing}

The success of X-ray tomography techniques in medical, geological, biological and other material sciences has led to its application in food science and technology.

Dairy products: Quantitative determination of eye formation in cheese, Tracking microstructural evolution (Ice-cream, mayonnaise and cheese samples), fat microstructure (yogurt), microstructure of loose-packed and compacted milk powders [8].

Meat: Quantification of salt concentrations (cured pork), microstructural characterization (chicken Nuggets), prediction of salt and water content (dry cured hams), intramuscular fat level and distribution (processed meat), salt and fat distribution analysis (salmon), and sodium quantification (pork).

Bakery products: Pore structure of bread crumbs, Effect of crumb morphology on water migration and crispness retention, Bubble growth and foam setting during bread making, structural parameters and starch crystallization (cake), effect of fat and sugar (sugar-snap cookies), investigation of bubble size distribution, growth and setting of gas bubbles (wheat flour dough).

Fruits and vegetables: Detect water core disorder and characterization of 'Braeburn' browning disorder (apples), quantification and characterization of internal structure (pomegranate) and determining maturity (tomatoes).

Coffee beans and nuts: Post-harvest assessment of internal decay (chestnuts), microstructural changes induced by roasting (coffee beans) and insect behavior (pecan nuts).

\section{Conclusion}

Non-destructive quality evaluation of agricultural products has become a major area of interest for the agricultural processing industry. A number of non-destructive methods for internal quality evaluation have been studied by different researchers over the past eight decades. $\mathrm{X}$-ray and computed tomography imaging techniques are few of them which are gaining popularity now days in various fields of agriculture and food quality evaluation. These techniques, so far predominantly used in medical applications, have also been explored for internal quality

*Corresponding author: Vidhya M, Department of Food and Agricultural Process Engineering, Post-Harvest Technology Centre, Tamil Nadu Agricultural University, Coimbatore-641003, India, Tel: +91-0422-6611383; E-mail: vidhyavasagam18@gmail.com

Received April 14, 2017; Accepted May 05, 2017; Published May 11, 2017

Citation: Vidhya M, Varadharaju N, John Kennedy Z, Amirtham D, Manohar Jesudas D (2017) Applications of X-Ray Computed Tomography in Food Processing. J Food Process Technol 8: 673. doi: 10.4172/2157-7110.1000673

Copyright: $\odot 2017$ Vidhya M, et al. This is an open-access article distributed under the terms of the Creative Commons Attribution License, which permits unrestricted use, distribution, and reproduction in any medium, provided the original author and source are credited. 
Citation: Vidhya M, Varadharaju N, John Kennedy Z, Amirtham D, Manohar Jesudas D (2017) Applications of X-Ray Computed Tomography in Food Processing. J Food Process Technol 8: 673. doi: 10.4172/2157-7110.1000673

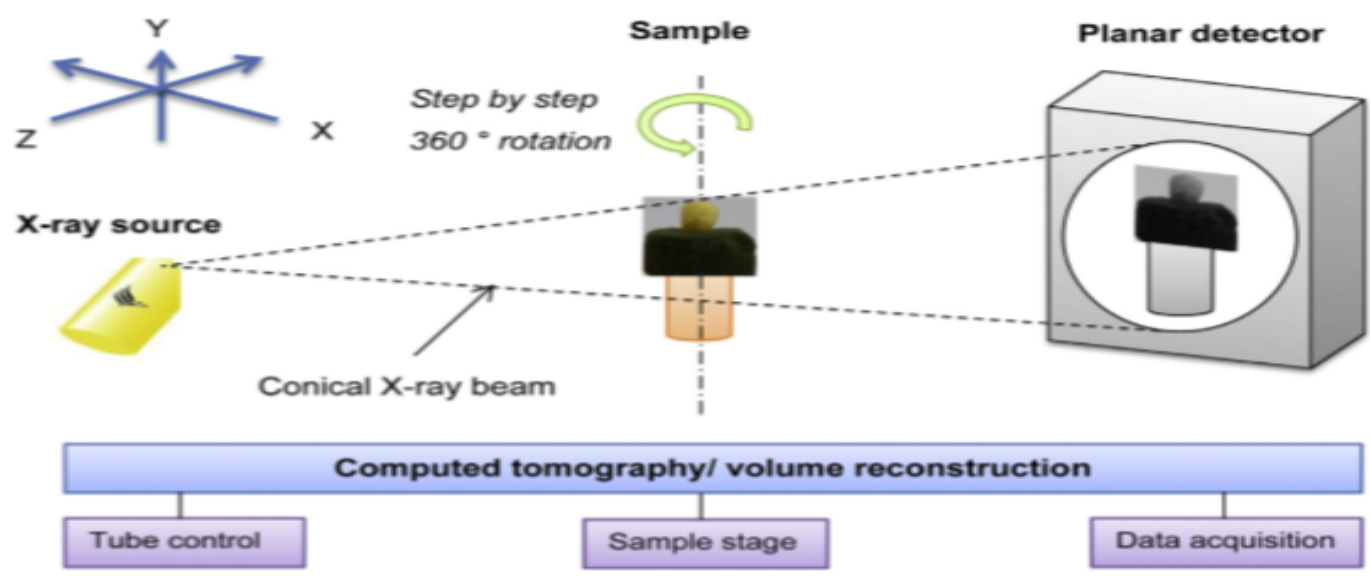

Figure 1: X-ray computed tomography: Schematic illustration.

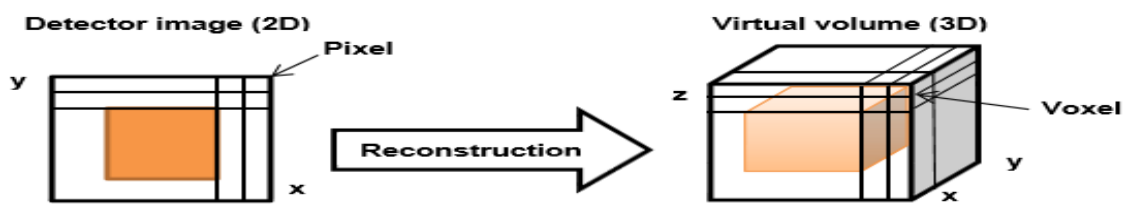

(a)

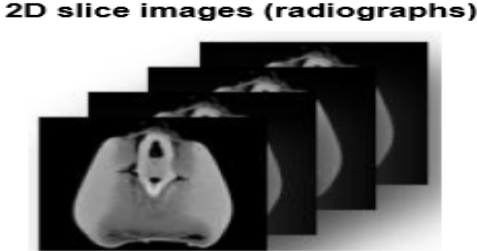

(b)

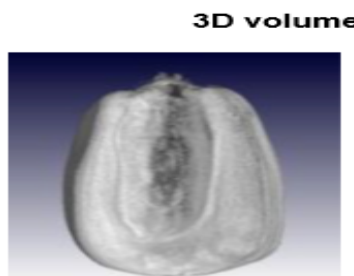

(c)

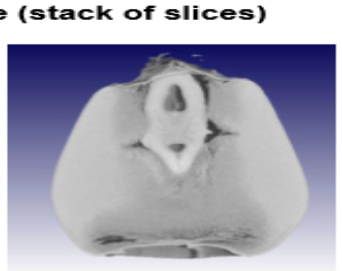

(d)

Figure 2: (a) The reconstruction process where a $3 \mathrm{D}$ volume is created from the $2 \mathrm{D}$ projection images and the illustration of (b) The stacking of $2 \mathrm{D}$ slices to obtain (c) A 3D image and (d) A clipped image.

inspection of various agricultural products non-destructively, when quality features are not visible on the surface of the products. Though, safety of operators and time required for tests are of concern, the nondestructive nature of these techniques has great potential for wide applications on agricultural produce. Compared to other commonly used techniques such as bright-field imaging, light microscopy, CLSM, TEM, SEM, or MRI, X-ray micro-CT provides a much more detailed and more reliable description of $3 \mathrm{D}$ structure and is, thus, gradually becoming a much-used tool in the study of food materials.

\section{References}

1. Lim KS, Barigou M (2004) X-ray micro-computed tomography of cellular food products. Food Res Int 37: 1001-1012.

2. Falcone PM, Baiano A, Zanini F, Mancini L, Tromba G, et al. (2005) Threedimensional quantitative analysis of bread crumb by X-ray microtomography. J Food Sci 70: 265-272.

3. Besbes E, Jury V, Monteau JY, Le Bail A (2013) Characterizing the cellular structure of bread crumb and crust as affected by heating rate using X-ray microtomography. J Food Eng 115: 415-423.

4. Adedeji AA, Ngadi MO (2011) Microstructural characterization of deep-fat fried nuggets using X-ray micro-computed tomography. J Food Process Eng 34: 2205-2219.

5. Chevallier S, Reguerre A, Le Bail A, Della Valle G (2014) Determining the cellular structure of two cereal food foams by X-ray micro-tomography. Food Biophysic 9: 219-228
6. Verboven P, Kerckhofs G, Mebatsion HK (2008) 3D gas exchange pathways in pome fruit by X-ray CT. J Food Eng 123: 67-77.

7. Donis-Gonzalez IR, Guyer DE, Fulbright DW, Pease A (2014a) Post harvest non-invasive assessment of fresh chestnut (Castanea spp.) internal decay using computer tomography images. Postharvest Biol Technol 94: 14-25.

8. Fulladosa E, Santos-Garces E, Picouet P (2010) Prediction of salt and water content in dry cured hams by computed tomography. J Food Eng 96: 80-85.

9. Magwaza L, Opara UL (2014) Investigating non-destructive quantification and characterization of pomegranate fruit internal structure using X-ray computed tomography. Postharvest Biol Technol 95: 1-6.

10. Chawanji A, Baldwin A, Brisson G, Webster E (2012) Use of X-ray micro tomography to study the microstructure of loose-packed and compacted milk powders. J Microscopy 248: 49-57.

11. Needhirajan S, Karunakaran C, Jayas D, White N (2006) X-ray CT image analysis to explain the airflow resistance difference in grain bulks. Biosystem Eng 94: 545-555.

12. Santos-Graces E, Laverse J, Gou P, Fulladosa E, Frisullo P, et al. (2013) Feasibility of X-ray micro CT for microstructure analysis and its relationship with hardness in non-acid fermented sausages. Meat Sci 93: 639-644. 